\title{
Zeitgeist ou espírito alemão: etno-história de germanidade e instituição da escola em Santa Catarina
}

Ademir Valdir dos Santos

\section{Resumo}

A história da educação enfatiza a contribuição do projeto da Companhia de Jesus na institucionalização da escola no Brasil, destacando influências jesuíticas. Este estudo está embasado na premissa de que tal abordagem escamoteia a complexidade de fatores culturais dos processos de instituição da escola nas diferentes regiões brasileiras, aliando-se à hipótese de que a presença de componentes simbólicas e materiais teutas caracteriza um peculiar processo de elaboração de germanidade em Santa Catarina. 0 objetivo é discutir o espírito alemão - Zeitgeist - e processos de institucionalização da escola. A metodologia tem por base um corpus documental: relatos de viajantes, imprensa, relatórios da direção de uma companhia de colonização, legislação, livros didáticos e caderno escolar. A perspectiva analítica é construída sob perspectiva etno-histórica, discutida à luz de outras pesquisas nucleadas no debate sobre as relações entre a imigração alemã e a educação. Os resultados indicam que o fator linguístico, amalgamado a elementos étnicos e à produção de identidades individuais e coletivas, embasa a compreensão de processos de instituição da educação escolar formal, considerando tanto os modos históricos de organização das escolas alemãs primordiais como daquelas teuto-brasileiras. Apontam ainda que a introdução, manutenção e difusão de elementos culturais e identitários de base germânica que ocorre desde o século XIX, em contextos ora harmoniosos, ora conflituosos, contribuiu para erigir um estatuto histórico de germanidade em Santa Catarina.

\section{Palavras-chave}

Educação - Imigração alemã - Germanidade.
I- Universidade Federal de Santa Catarina, Florianópolis, SC, Brasil. Contato: ademir.santos@ufsc.br 


\section{Zeitgeist or German spirit: ethnohistory of Germanness and the establishment of schools in Santa Catarina}

Ademir Valdir dos Santos

\begin{abstract}
History of Education has emphasized the contribution of the project of the Company of Jesus to the establishment of schools in Brazil, highlighting the Jesuit influence. This study is grounded on the premise that such an approach obscures the complexity of the cultural factors of the establishment of schools in different Brazilian regions, and on the hypothesis that the presence of German symbolic and material components has been characteristic of the unique development of Germanness in Santa Catarina state, Brazil. The study aims to discuss the German spirit - Zeitgeist - and the establishment of schools. The methodology is based on a documentary corpus: travelers' accounts, press, reports of the board of a colonization company, legislation, textbooks and a school notebook. Analysis has been conducted from the ethno-historical perspective, discussed in the light of other research on the relations between the German immigration and education. Findings have indicated that the linguistic factor, amalgamated with ethnic elements and the production of individual and collective identities, underlies the understanding of the establishment of formal education, considering primary the historical modes of organization of both German schools and German-Brazilian schools. Findings have also indicated that the introduction, maintenance and dissemination of Germanic cultural and identity elements since the nineteenth century, both in harmonious and in conflicting contexts, has contributed to erect a historic status of Germanness in Santa Catarina.
\end{abstract}

\section{Keywords}

Education - German immigration - Germanness.
I- Universidade Federal de Santa Catarina, Florianópolis, SC, Brasil. Contact: ademir.santos@ufsc.br 


\section{Introdução}

No campo da história da educação, constitui aspecto deveras examinado que a instituição da escola foi matizada pela Companhia de Jesus. Coube aos jesuitas a gênese e manutenção, de modo crescente até a metade do século XVIII, de atividades educacionais desenvolvidas nos domínios portugueses. Tal movimento conjugou a ação missionária catequética à instrução para as primeiras letras durante as primeiras décadas de povoamento e colonização, prosseguindo com a fundação de colégios. De acordo com o jesuíta Leonel Franca, "a obra educativa dos colégios da Companhia foi um dos fatores mais eficientes da contra reforma católica" (FRANCA, 1952, p. 6). Quanto à organização, segundo esse padre, que traduziu o Ratio Studiorum, ou Plano de Estudos, tal código reuniu prescrições pedagógicas que balizaram as atividades de mais de 578 colégios e 150 seminários.

Já de acordo com Saviani $(2007$; 1983), no Brasil, as perspectivas teórico-metodológicas que caracterizam a ação dos jesuítas expressaram tanto uma tendência quanto uma corrente de base humanista, inicialmente tradicional, depois moderna. E, conforme concepções da filosofia da educação, há uma periodização segundo a qual a tradição educacional mesclou, de modo equilibrado, uma vertente religiosa a outra leiga, mantendo tal arranjo certa hegemonia histórica até 1930; na fase posterior, avançou a "versão moderna em detrimento da tradicional" (SAVIANI, 1983, p. 20).

0 objeto deste estudo está centralizado no Zeitgeist, o "espírito alemão". Mas qual a relação entre a herança jesuítica e esse componente étnico-cultural germânico? Recorremos à escrita de Franca, porque, nas suas considerações sobre o Ratio, indica que o projeto da Companhia de Jesus foi ajustado e recebeu contribuições do Zeitgeist. Destaca que a pedagogia jesuíta não foi revolucionária ou inovadora, estando a germanidade intimamente vinculada às origens e ao legado jesuítico:
Ao espírito de uma época, ao Zeitgeist dos alemães, não se furta nenhum sistema pedagógico, nem mesmo quando conscientemente se organiza para combatê-lo. 0 código de ensino dos jesuítas não se pôde subtrair a esta necessidade e traz, indelével, o cunho do século XVI. (FRANCA, 1952, p. 27-28).

Com base em tal premissa, caminhamos pelo escopo de discutir a gênese e permanência do Zeitgeist. Especificamente, problematizamos fenômenos etno-históricos que influenciaram a institucionalização da educação escolar em Santa Catarina, nutrindo-se do espírito alemão. 0 núcleo está na caracterização de um tipo de instituição educacional vista como estrangeira, implantada em Santa Catarina com o movimento humano da imigração alemã, principiado no século XIX: a deutsche Schule ou escola alemã, mais tarde denominada teuto-brasileira (SCHADEN, 1966). A hipótese postula que a presença de componentes simbólicos e materiais, imaginários e representações associados à cultura germânica é expressão do espírito alemão: o Zeitgeist está na origem e, ao mesmo tempo, deriva de um processo de elaboração da germanidade. Haveria, então, uma Alemanha perdida em Santa Catarina.

A metodologia tem por base um corpus que reúne fontes documentais coletadas no Brasil e na Alemanha: relatos de viajantes, imprensa, relatórios da direção de uma companhia de colonização, legislação, livros didáticos e caderno escolar. A discussão é pautada por referenciais dos escritos e fontes selecionados, notadamente pesquisas realizadas e em andamento que apontam para a centralidade de instituições escolares.

Revigoramos experiências e vivências de tempos e espaços num plano de elaboração da cultura em que fatores étnicos, entre eles a instituição da escola, ocupam um amplo locus de significados. Convidamos a navegar pelos mares da história, sujeitos a desejadas calmarias, mas também a ventos e tempestades nutridos nas 
metamorfoses paridas num combate entre uma espécie de germanismo primitivo transplantado e eólicos açoites de brasilidade: Zweikampf!

\section{Navegando pelos primórdios: da} calmaria da chegada ao olho do furacão

Europeus de diversas procedências aportaram nas terras luso-brasileiras com o processo colonizador iniciado no século XVI. Ao longo desse arco cronológico, foram produzidos escritos que tratam da chegada e instalação de viajantes individuais e de famílias estrangeiras no Brasil. Entre descrições etnográficas pitorescas, literárias ou acadêmicas, desvelam-se aventuras e vicissitudes reservadas pelo Novo Mundo a aventureiros e convidados, num ambiente que mesclou o inóspito, bárbaro e inculto ao atrativo, fascinante e quiçá enriquecedor. Inferno ou paraíso?

0 alemão Carl Seidler, que veio a serviço de Dom Pedro I, escreveu Dez anos no Brasil. A primeira edição foi publicada em Leipzig, em 1835, e revela antipatias quanto à cultura local. Segundo a Biblioteca Histórica Brasileira, que editou textos de viajantes como Rugendas, Debret, Davatz, von Koseritz, Burmeister e do Príncipe Adalberto da Prússia,

0 seu autor, aventureiro alemão, vindo ao Brasil com o intuito de fazer fortuna rápida, aqui chegando viu seus sonhos desfeitos. De volta à terra natal escreveu um livro cheio de animosidades sobre o país que não o tornara milionário [...]. (SEIDLER, 1941, p. 5).

Vejamos como Seidler (1941, p. 224) descreveu a viagem marítima de Laguna (no sul catarinense) até o desembarque na cidade do Desterro, hoje Florianópolis:

Teríamos assim vencido cêrca de metade da nossa viagem, quando de repente um dos marinheiros subiu ao convés e murmurou ao ouvido do capitão que o navio estava fazendo água. Cambaleando de mêdo e de cachaça, desce êle logo ao porão. [...] Com mais um pouco descobriu-se o rombo: era um buraco feito pelos ratos, que já fôra remendado mas se reabrira com as violentas batidas no banco de areia à nossa saída da barra. [...] Pouco depois nos achávamos entre a ilha de S. Catarina e o continente, ao abrigo de altas montanhas, onde o vento não podia mais castigar-nos tanto e onde o mar também serenou. Pelas duas da madrugada arriamos âncoras bem em frente à cidade do Destêrro.

Mesclando ironia e desejo de desvendar, a imaginação passeia pelo cenário acompanhada por vento e medo, calmaria e promessa:

Levado por invencível curiosidade, impelido pelas mais vivas esperanças subí com a noite enluarada ao balouçante convés, para contemplar a ilha envôlta em nuvens e a cidade meio oculta na semi-escuridão, cidade da qual durante minha estada no Brasil eu ouvira tanta coisa miraculosa. Os naturais da ilha chamam-na com razão o "jardim do Brasil"; ela merece êsse nome pela sua luxuriante vegetação, seu clima temperado extremamente saudável, e as encantadoras vistas que se tem para longe, de quase todos os pontos. Outrora esse jardim era lugar de destêrro de criminosos portugueses, de onde o nome da capital; realmente por êsse preço era-se tentado a praticar algum crime para também ser desterrado, pois era ceder um instante ao inferno em troca do resto da vida no céu. Muito especialmente me haviam gabado a cordialidade e gentileza dos moradores, a beleza e sociabilidade das senhoras, a barateza dos víveres e o romântico dos passeios; que milagre, pois, que eu hoje desejasse que amanhecesse algumas horas mais cedo para que, quanto antes melhor, se me abrisse êsse fabuloso paraíso do novo mundo. (SEIDLER, 1941, p. 224). 
Outros olhares foram deitados sobre Santa Catarina. 0 livro Viagem pelo sul do Brasil no ano de 1858, é fruto das incursões pelas regiões meridionais de Avé-Lallemant, médico e explorador botânico que chegou em 1837 e, a princípio, dedicou-se à saúde da população no Rio de Janeiro por 18 anos. Voltou à região natal, mas, em 1858, retornou às águas e terras brasileiras como médico na Novara, uma fragata que iria viajar pelo mundo sob o comando do explorador Humboldt ${ }^{1}$. Devido a desentendimentos a bordo, desembarcou no Rio e recomeçou a clinicar. Depois, mediante o apoio mecenático de Dom Pedro II, partiu para novas viagens. Neste excerto dramático, fala dos alemães em Santa Catarina, recontando o destino de imigrantes que aportaram tendo como destino a colônia Santa Isabel:

Em dezembro de 1846 chegaram ao Rio de Janeiro, no navio "Erídano", setenta a oitenta imigrantes alemães. Ninguém os chamara, ninguém sabia o que fazer com eles; estavam sós e abandonados na praia... [...] Lá vi a gente na sua aflição; alguns estavam doentes; fiz por êlles o que pude; tive até de assistir a uma senhora que ali deu à luz em plena rua.

[...] a gente teve de ficar quarenta e oito horas na Praça do Palácio, ao relento, sofrendo terrivel tempestade de dezembro, e teria ficado sem abrigo, se não a socorressem os moradores [...]. Depois de onze dias de triste estada, foram em sua maioria levados num navio de guerra brasileiro para as províncias do sul e não ouvi mais falar neles. (AVÉ-LALLEMANT, 1953, p. 117-8).

A seguir, conta seu reencontro com alguns imigrantes em território catarinense:

1- 0 naturalista alemão Humboldt é um dos pais da Geografia. Em 1800, apesar de não completar a viagem que penetrou as fronteiras para além da Amazônia Venezuelana, acabou inspirando estudiosos a posteriormente finalizar e registrar o itinerário e as aventuras da missão original.
Em 3 de julho desci o Rio dos Bugres e cheguei a uma casa bem carpintejada, diante da qual estava um homem. Devia entregar-lhe uma carta do Presidente e entrei na casa.

Ali dançavam diante de um realejo alguns rapazes e moças, todos contentes como se fossem a uma romaria. Scheid, o dono da casa, de Donnersberg, na Baviera Renana, sentou-se e falou-me da colônia alemã de Santa Isabel, em cujo centro me achava. Logo que começou a contar-me seu destino no Brasil, ressurgiram-se diante dos olhos os imigrantes do "Erídano" do ano de 1846. Scheid e sua família estavam entre eles; estivera doente naquele barracão de lenha e provàvelmente eu o tratara. (AVÉLALLEMANT, 1953, p. 117-118).

0 viajante exprime seu otimismo quanto ao destino dos imigrantes e de sua descendência:

Os imigrantes do "Erídano" foram trazidos para Santa Catarina, no princípio do ano de 1847, quando se começava [...] a fundação de uma colônia que recebeu o nome da jovem princesa dona Isabel. Venceram sem grande esforço as primeiras dificuldades encontradas em terra estranha com uma agricultura que não lhes era familiar e desde então vivem como gente feliz e abastada. Aliás Scheid tornou-se muito abastado. Possui 1200 jeiras de terra, 19 burros, muitas vacas de leite e boa casa de residência, ainda não concluída, para onde está mudando seu bom moinho. Em volta dele medram seis filhos vigorosos e sadios. Os mais velhos auxiliam o pai. Vive também com ele a velha mãe, de setenta e nove anos, mulher de vigor realmente incompreensível; trabalha no campo, nas altas encostas e no sábado dança a valsa com as rijas netas tão bem como quando estava, há sessenta anos atrás, em Donnersberg. (AVÉ-LALLEMANT, 1953, p. 117-118). 
0 que essas linhas indicam é ratificado por Seyferth (1999, p. 81), ao evidenciar a perpetuação nas áreas coloniais de formas características de atividade agrícola, sistematizadas na pequena propriedade e através do padrão de distribuição de terras, destacando os modos de constituição dos núcleos familiares - resiliências que se consolidaram nos séculos seguintes, deixando traços hoje detectáveis apesar de mudanças econômicas: "Nas áreas rurais alemãs dessa época, em geral uma família compunha-se de três gerações vivendo na mesma propriedade". Apresenta-se a imigração como uma das vias pelas quais a germanidade reverberou, instalando contrastes culturais e delineando discrepâncias entre os referenciais culturais teuto-europeus e a nacionalidade brasileira, sobre alicerces étnicos.

Focalizamos agora o depoimento sobre a vida no Brasil no século XIX assinado por Ina Von Binzer. Sua escrita é intitulada Os meus romanos: alegrias e tristezas de uma educadora alemã no Brasil. Surgiu na década de 1880 e a primeira versão em português data de 1956.

A alemoa Ina era uma preceptora contratada para educar os filhos de abastadas famílias paulistas ${ }^{2}$. Redigiu suas impressões abordando a realidade social, econômica e cultural daqueles tempos, caracterizando-os como de pouca civilidade e de desconhecimento do saber universal, para ela identificadores da elite brasileira. Esses aspectos foram descritos e avaliados pela professora alemã, que tentou conciliar os princípios da pedagogia que conhecia e a rigidez dos hábitos germânicos à escolarização que devia protagonizar. Ina demonstra sensibilidade ao questionar a eficácia do seu aprendizado para lidar com a infância. Referindo-se a um austero pedagogo, pondera em correspondência à amiga Grete:

2- Utilizamos esta terminologia propositadamente, pois notamos em incursões que a palavra destacada continua sendo empregada em Santa Catarina, sobretudo na oralidade dos descendentes bilíngues, que a aplicam ao invés do adjetivo alemã. Referenciais da etnolinguística ajudam a explicar esse fenômeno derivado de um processo histórico de (re)aprendizado idiomático (APPEL; MUYSKEN, 1997).
Você sabe quem afundei hoje nas profundezas mais profundas da minha mala? 0 nosso Bormann, ou melhor, suas 40 cartas pedagógicas que não têm aqui a menor utilidade. E confiava tanto nelas! (BINZER, 1982, p. 21).

0 teor desses escritos desnuda uma estigmatizante etnicidade. Semeada pelo discurso de Ina Von Binzer está presente a típica interjeição $A c h$ !, à qual recorre para realçar as estupefações causadas pelas contradições entre a cultura germânica e a (luso)-brasileira. No momento em que deixava São Paulo para trabalhar numa fazenda do interior, exprime:

Não há dúvida, Grete, "ela vai mesmo para o campo”. Mas por sorte, não é longe; apenas duas horas de estrada de ferro daqui até a estação que serve essa fazenda. De qualquer forma é um consôlo, porque assim a gente não fica completamente afastada do mundo.

As crianças, três meninas, parece que são de boa índole e a mãe, D. Maria Luísa, é conhecida por sua delicadeza e tem grande simpatia por tudo o que é alemão. Ela mesma teve professoras alemãs e seu único filho está sendo educado na Alemanha.

Somente já me disseram que vou achar muito primitiva a vida nessa fazenda instalada à moda antiga do país.

Sinto algum receio quanto a esse gênero e ao mesmo tempo estou curiosa de conhecer a autêntica vida do campo brasileira sobre a qual centenas de pessoas que visitam o Brasil não conseguem formar uma opinião. Nesse particular nós, as professoras, levamos vantagem em relação aos comerciantes e outros europeus dentre os quais muito poucos se afastam das cidades marítimas, e a maioria depois de 10 ou 20 anos retorna à Europa sem conhecer o resto do país e muito menos a vida real dos brasileiros; ao passo que, convivendo na intimidade deles, temos ocasião de 
observar de perto toda a trama. (BINZER, 1982, p. 94, grifos nossos).

0 que abordamos é ratificado por trabalhos que discutem a História da Educação de regiões meridionais do Brasil (SANTOS, 2014; 2012a; 2009; SANTOS; VECHIA, 2013; FIORI, 2003; RICHTER, 1992; SEYFERTH, 1990). Entre os pesquisadores, há um acordo quanto a vinculações entre cultura, etnia e identidade, reafirmando a germanidade como construto, vindo ao encontro da seguinte conceituação:

[...] abordar os aspectos da etnia significa: a. atentar para uma perspectiva das relações entre os sujeitos e grupos sociais considerando sua língua, seus costumes e tradições, sua religião, suas instituições sociais;

b. conjugar, de forma simultânea, os múltiplos dados relacionais das práticas sociais a sentimentos de pertencimento a um mesmo povo ou nação em que há ligações defınidas pela consanguinidade, pelo convívio em um mesmo lugar geográfico e por um processo histórico constitutivo de relações nos planos econômico, social e político;

c. partilhar elementos simbólicos e de base material que expressam significados nos processos relacionais compartilhados no âmbito da cultura;

d. analisar o engendramento da produção e reprodução cultural considerando a dinâmica mesma de sua operação, levando em conta as interferências, condicionamentos e participações dos sujeitos e grupos sociais. (SANTOS, 2012a, p. 542).

0 citado Avé-Lallemant anunciou ainda a presença de crianças e a necessidade de escola. Por um momento, parecia-lhe estranho que um empreendimento educacional não tivesse brotado da iniciativa dos imigrantes:

Além disso, fervilhavam crianças em toda parte. De onde vinham tantas crianças?
É um lindo grupo de travessos, todos de boa aparência, nas manhãs de domingo, quando as mães lhes lavam o rosto e, com algum esforço, fazem duas trancinhas nos cabelos das meninas. Veio-me no entanto um pensamento melancólico ao contemplar a querida criançada. Decerto a augusta princesa Dona Isabel não sabe que [...] as crianças não tem um mestre-escola, com quem possam aprender a palavra de Deus e a ler, escrever e contar e também nenhum sacerdote na vizinhança, que celebre o serviço divino aos domingos. Mas ninguém se interessou por isso [...]. Creio, aliás, que as crianças não ficarão por muito tempo sem mestre. (AVÉ-LALLEMANT, 1953, p. 119).

Alude a um espaço para os ritos religiosos, que no futuro poderia abrigar o ensino das primeiras letras:

Há uma capela pequena e simples - e já foram construídas duas - faltando apenas um sacerdote permanente. 0 número de habitantes deve elevar-se de 500 a 600; formam 71 famílias, que se dividem em evangélicos e católicos. (AVÉ-LALLEMANT, 1953, p. 119).

Seguimos compartilhando uma perspectiva antropológica segundo a qual um dos núcleos da imigração alemã é a força institucional na difusão étnica:

[...] algumas instituições comunitárias [...] apareceram como divulgadoras dos valores étnicos, preservados pelos imigrantes e transmitidos de uma geração a outra. A língua materna e a cultura nacional seriam preservadas através da escola, da igreja, das associações, mas acima de tudo através da palavra escrita, no sentido de marcar a diferença de um grupo em relação aos outros. Estas instituições formais serviram de veiculadoras $e$ perpetuadoras da etnicidade. (SEYFERTH, 1990, p. 82, grifos nossos). 
Içando as velas: os ventos históricos conduzem à escola

Já elencamos fatores históricos responsáveis pelo enraizamento de hábitos alemães: a imigração e criação de colônias; o progresso de atividades produtivas e a inicial institucionalização da família e da religião. Agora, aprofundamos a discussão sobre uma das rotas pelas quais a germanidade frutificou: a educação escolar. Para tanto, é necessário retomar argumentos presentes na introdução em que citamos Franca (1952) para clarificar nosso objetivo. Isso faz emergir concepções educacionais vinculadas ao papel de instituições religiosas, ao mesmo tempo em que nos permite trazer à tona a Reforma protestante e seu ideário, destacando o luteranismo. Sublinharemos a circulação de ideias que dali deriva e influencia a configuração etno-histórica da diversidade pedagógica em Santa Catarina, buscando correlação com a germanidade.

Nesta argumentação, é essencial considerar a presença, entre os imigrantes, de grupos de adeptos da fé luterana. 0 imigrante alemão luterano é entusiasta da escola (FISCHER, 1984). A herança cultural religiosa do reformador explicita que é vital manter escolas para as crianças e jovens. E, no ambiente das colônias catarinenses, estavam vivas as exortações que Martinho Lutero apresentou em dois documentos clássicos: "Uma prédica para que se mandem os filhos à escola", escrito em 1530 e "Aos conselhos de todas as cidades da Alemanha para que criem e mantenham escolas cristãs", de 1524. A voz de Lutero soprava como ventos vigorosos entre os imigrantes protestantes, alertando para o fato de que não enviar os filhos à escola contribui para a destruição do reino de Deus, correspondendo a uma estratégia de Satã:

Entre suas artimanhas uma das mais importantes (se é que não é a mais importante) consiste em aturdir e enganar as pessoas simples de tal maneira que não queiram mandar seus filhos à escola nem encaminhá-los para o estudo. (LUTERO, 1995, p. 331).
Eis mais um dos alicerces do Zeitgeist, até hoje vivaz, resultado das ilações de fé entre imigração, religião e instituições escolares, que solidificou a atividade comunitária. Segundo Beck (1995, p. 301), tudo isso servindo "para justificar o empenho pela boa educação que tem caracterizado as comunidades e os líderes luteranos desde a Reforma. Como Lutero, sentimo-nos responsáveis pelas gerações futuras. É por isso que lutamos na e pela educação”.

Outro elemento a ressaltar é a imprensa em língua alemã. Impulsionada pela cultura teuto-europeia, passou a ser semeada ao vento: cinzas que viriam a nutrir uma fênix germânica. É o caso do Der Urwaldsbote, editado desde 1893 e do Sonntagsblatt für die Evangelischen Gemeinden in Santa Catarina, impresso a partir de 1895. Os jornais representaram um elo entre os sujeitos, ao mesmo tempo em que serviram como base para uma circulação capilar do germanismo.

Apresentamos uma edição do Jornal de Joinville, publicada em 22 de maio de 1926 sob o título "O Municipio de Joinville - 18511926”, comemorativa dos 75 anos de fundação da originalmente chamada Colônia Dona Francisca $^{3}$. Segundo o editor, essa matéria já teria sido publicada num jornal carioca em 1871. Focaliza a prosperidade nas décadas fınais do século XIX, decorrente da presença alemã. Esse periódico era um típico artefato cultural germano-português, pois mesclava língua estrangeira e vernáculo. Destacava as instituições para o atendimento infantil, num momento em que noutras regiões havia raridade de oferta escolar, como lembra Werebe (1995, p. 382), ao tratar da transição do Império para o período republicano: "a República veio encontrar o país, no terreno educacional, com uma rede escolar primária bastante precária, com um corpo docente predominantemente leigo e incapaz". Mas $O$ Jornal de Joinville registra:

3- A imperial Colônia Dona Francisca abrigava o território correspondente à atual Joinville, hoje o maior e um dos mais prósperos municípios de Santa Catarina. 
A população da colônia nos cinco primeiros annos attingio a 1428 almas e elevou-se a 3678 dez annos depois de sua fundação, sendo protestantes lutheranos 2993 e 685 catholicos.

[...] Escolas existem 15; 3 publicas sendo 2 para o sexo masculino e 1 para o feminino, e 12 particulares, sendo 11 para ambos os sexos e 1 collegio para o feminino, nas quaes ensinam os idiomas allemao e portuguez.

Estas escolas foram frequentadas no anno passado por 790 meninos de ambos os sexos.

Relativamente à instrucção é a villa de Joinville um dos pontos do império em que Ella marcha com passos de gigante; todos os meninos (com bem pouca excepção) frequentam as aulas, uns calçados, outros descalços, outros em mangas de camisa, finalmente todos vão à fonte principal da instrucção bebel-a, uns conforme podem, outros conforme querem; e assim mais ou menos instruem-se de modo a serem uteis a si e ao seu paiz.

Como a maior parte dos meninos pertencem à famílias allemãs, vão-se habituando com os usos e costumes europeus, não lamentando de futuro o terem de pedir á outros para assignarem "a rogo", como infelizmente entre nós, os brasileiros ainda succede. (JORNAL DE JOINVILLE, 1926).

Outros referenciais analisam a implantação de escolas, discutindo o povoamento por colonos alemães de maioria luterana nas terras comercializadas pela Companhia Colonizadora Hanseática de Hamburgo:

[...] em 1904 [...] já havia quatro escolas em Humboldt: na "cidade" (Stadtplatz), na estrada Isabel (Isabella-Strasse), na estrada Paulo (Paul-Strasse) e na estrada Bonpland e Humboldt (Bonpland und Humboldt Strasse). Em outro distrito, Itajaí-Hercílio, também já funcionavam cinco escolas: Hammonia, Sellin, Rafael, Neu-Bremen e Neu-Zürich.
Havia uma em São Bento e outra em Piraí. (SANTOS, 2012a, p. 544-545).

Algumas haviam sido fundadas por sociedades escolares particulares que tinham como membros as famílias dos imigrantes, as Schulverein ou Schulgemeinde. Santos (2012a, p. 547) ainda documenta que existia subvenção financeira para a abertura e funcionamento das escolas por parte da Companhia, devidamente registrada entre os gastos e investimentos nos relatórios dos diretores daquele empreendimento das regiões norte e nordeste de Santa Catarina.

Já sobre os professores, consta que a docência era uma das atividades do pastor luterano, embora, em algumas localidades, o professor fosse indicado pelos próprios colonos, numa escolha entre os que já possuíam escolarização. Em outras situações, o docente vinha de fora e era instalado na comunidade, recebendo moradia (às vezes conjugada com o prédio escolar) e passando também a cultivar a terra e a criar animais. Segundo Willems (1980, p. 280-281), o salário do professor era rateado entre os interessados no funcionamento da "escolinha". De acordo com memórias de velhos descendentes de imigrantes colhidas por Santos (2011), a escola era fundada, construída e mantida com os esforços comunitários.

Verifica-se ainda a possibilidade de atuação de professores vindos da Alemanha, como foi o caso do pastor Aldinger, que atuou em Hammonia. Nascido em 1869, formado em teologia e com doutoramento em filosofia, foi nomeado administrador da Sociedade Central Evangélica para Colonos Alemães e Imigrantes em 1889. Lecionou para colonos na Europa. Mas o que teria impulsionado Aldinger foram seus projetos de se radicar entre a mata no sul brasileiro. Motivado, chegou em 1901, aos 32 anos de idade, com mais 47 imigrantes. Paul Aldinger é reverenciado por ser protagonista da comunidade evangélica e pela intensa atividade educativa e cultural. Além de fundar escolas, criou o Hansabote (Mensageiro de Hansa), jornal escrito em alemão, que circulou até 1913. 
Especulamos sobre como funcionava a escola alemã primária, analisando relatórios do Arquivo Estadual de Hamburgo, que descrevem minuciosamente como atuavam professores da Colônia Hansa entre os anos de 1899 e 1911. Dizem que se ensinavam religião, cálculo, leitura, ditado, escrita, redação, história mundial, português, história natural, canto, trabalho manual e geografia; às vezes, até latim (AUSZUG..., 1905).

0 conteúdo dessas fontes permite afirmar que a comunicação era feita predominantemente no idioma alemão (Hochdeutsch) ou em dialetos. Um mestre-escola registrou que misturava conteúdos estrangeiros aos brasileiros: falava às crianças de tipos de Kolibri (beija-flor). Já a história nacional (Heimatkunde) tratava da descoberta do Brasil e da colônia, bem como do Vale do Itajaí. E a geografia estudava a própria Santa Catarina, Paraná e Rio Grande, bem como as Américas e a Europa (JAHRESBERICHT..., 1905).

Quanto aos materiais didáticos, incluíam importados ou publicados por editoras que foram sendo implantadas no Brasil, como a Rotermund, ativa a partir de 1877 e fundada por um imigrante que foi pastor, professor e jornalista. Destacamos a circulação do Allgemeiner Handatlas in sechsundachtzig Karten mit erläuterndem Text, ou seja, Atlas geral em oitenta e seis cartas (mapas) com texto explicativo, datado de 1881, que traz uma cartografia com a precisa localização das colônias alemãs e do Uruguai (SüdostBrasilien mit den Deutschen Kolonien und Uruguay). Exemplificamos com outros livros ou manuais que auxiliaram na consolidação da germanidade: livros de leitura como o Deutsches Lesebuch für Brasilien für das erste und zweite Schuljahr nebst Anhang für den deutsch-portugiesischen Unterricht, de Grimm e Bürger, e o Mein Kleines Lesebuch für das 2. Schuljahr mit Scherenschnitten von Therese Kollatz - herausgegeben von Deustchen Evangelischen Lehrerverein von Rio Grande do Sul; na disciplina de história, o Grundriss der Geschichte Brasiliens, de Stysinski; o Praktische
Rechenschulle in der heften für Deutsche Schulen in Brasilien (4. heft), de Büchler, usado na matemática; e o Landeskunde der Vereinigten Staaten von Brasilien - Für deutsche Schulen in Brasilien, do autor Sellin, para a geografia.

Apontamos ainda uma literatura bilíngue que evidencia interpenetração étnica. Constituem exemplos: Minha língua - Grammatica portuguesa para uso nas escolas allemãs no Brasil - Portugiesisches Sprachbuch für die deutschen Schulen in Brasilien, de Ebling-Rotermund; Portugiesisches Sprachbuch für Kolonieschulen e Arithmetica pratica em quatro partes, ambos de Büchler e A Orthoepia da Lingua Portugueza em exercicios para as Escolas Allemãs no Brasil, cuja primeira edição é de 1879 e foi preparada por Wilhelm Rotermund com a intenção de aperfeiçoar o português ensinado nas escolas de imigrantes.

Optamos também por explorar um caderno de tradução, utilizado numa escola teuto-brasileira. Temos garimpado por esses peculiares contentores de escritas, reunindo e analisando raros remanescentes preservados em arquivos particulares ou em museus. Sob nossa ótica, o caderno escolar autoriza e atribui valor à voz e à escrita dos alunos, permitindo uma aproximação do funcionamento didático-pedagógico das antigas salas de aula e de contextos históricos.

Emblemático é o caderno bilíngue do menino Kilian Tank. Foi identificado como lingua portugueza: tradução. Na capa, consta o ano de 1946. A arquitetura dessa fonte funciona como marca identitária de um tipo de escola. Folhear cadernos possibilita navegar pela história de sujeitos e seus contextos. No seu interior, geralmente se mesclam escritos e desenhos mais ou menos espontâneos distribuídos nas linhas e margens, marcas do aprendizado de uma infância paleolitica do processo histórico de escolarização, elaboradas nas páginas-parede do caderno-caverna pelo autor-estudante, pré-histórico de si mesmo. Por vezes, compondo uma estética própria, rupestre, que batizamos de 
marcas de uso e que partilha o espaço com as indefectíveis atividades e lições que atendiam às prescrições docentes, como cópias, ditados e lições de casa ou deveres. E, como todo aluno-construtor de cadernos sabe, aqui e acolá, deparamo-nos com semáforos que sinalizam em vermelho, geralmente correções e anotações do mestre. Conforme propõe Viñao (2008, p. 23):

Quem recorre aos manuais ou textos nos quais se propõe ou defende o uso do caderno escolar surpreende-se com o fato de, além de serem feitas considerações sobre os códigos de apresentação (cabeçalho da tarefa diária, epígrafe ou título de cada atividade, margens, adornos e ornamentações etc), dar-se ênfase, sobretudo, à "limpeza" e à ausência de manchas, folhas arrancadas ou anotações e desenhos intempestivos ou "selvagens", não controlados. A razão é óbvia: o "efeito estético" tem também um sentido ético, regularizador e disciplinar, e a "limpeza absoluta" supõe a "criação de hábitos”, ou seja, a sujeição a uma ordem de não-transgressão com referências moralizadoras.

Os cadernos dividem os lugares e tempos da sala de aula com os livros didáticos. Visitando-os, deparamo-nos com escritas infantis que reproduzem o teor de livros didáticos disponiveis na época em que foram preenchidos. Esse fato nos fez cotejar o teor de livros e cadernos que circulavam nas escolas dos imigrantes alemães e seus descendentes. Exemplo disso é a análise do manual para o ensino de português Kleine Portugiesische Sprachlehre, de autoria de Luise Ey, onde constam várias páginas que perfilam listagens de palavras e expressões em português e em alemão, impressas em tipos góticos. 0 excerto compilado na Tabela 1, extraído desse livrinho utilizado em escolas de Santa Catarina, embasa-se no método apresentado como Methode Gaspey-Otto-Sauer.
Tabela 1 - Lista de tradução constante na Segunda Lição (Zweite Lektion)

\begin{tabular}{c|cccccc}
\hline pai & Vatter & Mãe & Mutter \\
\hline \multirow{2}{*}{ homem } & \multirow{2}{*}{ Mann, Mensch } & Mulher & Frau \\
\hline \multirow{2}{*}{ touro,boi } & \multirow{2}{*}{ Stier, Ochs } & Vaca & Kuh \\
\hline cão & \multirow{2}{*}{ Hund } & Cadela & Hündin \\
\hline \multirow{2}{*}{ carneiro } & Hammel & Ovelha & Schaf \\
\hline cavalo & Hengst & Égua & Stute \\
\hline
\end{tabular}

Fonte: EY, Luise. Kleine Portugiesische Sprachlehre, 1936, p. 30.

Constatamos que, do mesmo modo, páginas do caderno de Kilian foram separadas em duas colunas, sendo que à esquerda estão registrados os termos e expressões em português e à direita, a tradução. Reafirmamos com Santos (2009) que cadernos e livros didáticos são elementos da cultura material que significam vivamente uma contínua construção da germanidade, de base etnolinguística.

Nessas análises, evidenciamos a centralidade dos contatos idiomáticos, de problemas e conceitos relacionados. Concordamos com Appel e Muysken (1996), que sustentam uma compreensão da humanidade balizada pela história dos povos e nações intimamente combinada à história das línguas que falam, a qual, simultaneamente, delineia relações de poder e dominação que têm por base aspectos sociais, psicológicos e linguísticos, pondo em evidência o embate entre ambientes culturais cujas línguas dominantes e minoritárias se confrontam e conseguem, em maior ou menor proporção, manter suas características primordiais.

\section{Navegação a contravento: sopram} ventos e tempestades

Alguns trabalhos assinalam que, nas primeiras décadas do século passado, ocorreu um processo de nacionalização capitaneado pelos governos federal e estadual, que utilizou o aparelho escolar das regiões de imigração europeia (PANDOLFI, 1999; MÜLLER, 1994). Calcou-se na 
prescrição de práticas culturais para a infância e juventude com ascendência estrangeira, imbuídas de valores e atitudes que pretendiam o aprendizado e inculcação não apenas da língua portuguesa, mas de um patriotismo devotado à nação brasileira. 0 período do Estado Novo (1937-1945), capitaneado por Getúlio Vargas, foi o momento de sua maior exacerbação, embora diversas expressões de nacionalismo viessem sendo gestadas desde a Primeira Guerra Mundial. Alimentadas pela legislação e por órgãos de gestão educacional, campanhas de abrasileiramento foram dirigidas às escolas de imigrantes e tinham o objetivo de orientar a ação pedagógica para uma consequente extinção do germanismo nas comunidades alienígenas.

Assim, ventos e tempestades da nacionalização impactaram principalmente nas colônias alemãs, tidas como "quistos étnicos" a varrer do mapa. Pleiteou-se que todo o material utilizado fosse vernacular. Nota-se que, em decorrência, houve uma fase de bilinguismo alemão-português, embora se detecte que, nas colônias de imigrantes de Santa Catarina, obrigou-se o uso exclusivo da língua portuguesa, sendo veementemente proibida a utilização do alemão não apenas no ambiente escolar mas também no conjunto das demais relações sociais, mediante ameaças persecutórias. Foram atingidas famílias e comunidades, assim como outras instituições sociais dedicadas a manifestações étnicas que usavam da língua ou de expressões culturais germânicas. 0 culto religioso luterano, o canto, a dança, o teatro, a ginástica, o tiro ao alvo e o bolão também foram proibidos, contribuindo nos conflitos. Como demonstra Santos (2014), tal processo ocasionou mudanças institucionais: as escolas alemãs foram sendo gradativamente moldadas como escolas teuto-brasileiras, para que se imprimisse sempre mais os modelos da desejada brasilidade, substituindo e até mesmo extinguindo a germanidade remanescente.

Por exemplo, o Programma de ensino das escolas isoladas das zonas coloniaes, expresso no decreto 1944, datado de 1926, rezava:
[...] considerando que, para as escolas dessas zonas, se torna necessária a organização de um programma que, sem augmento do estagio escolar, attenda aos problemas de desanalphabetização e do ensino da língua portuguesa. (SANTA CATARINA, 1926, p. 3).

Particularmente quanto ao ensino da língua vernácula, recomendava-se enfaticamente até mesmo a didática de atendimento do alunado. Para as crianças do $1^{\circ}$. ano, havia ênfase na escrita, leitura, linguagem oral e nos cantos:

$1^{\circ}$. - Leitura diária, no quadro negro, de nomes de objetos conhecidos dos alumnos. $2^{\circ}$. - Verificado que os alunos conhecem, com segurança, os nomes apresentados no quadro negro, far-se-á a traducção dos mesmos. Ex.: casa - Haus; chapéu - Hut; copo - Glass; boneca - Puppe, etc.

$3^{\circ}$. - Decomposição oral dos vocábulos em syllabas, de forma que o ouvido dos alumnos se familiarize com os elementos componentes das palavras estudadas. Ex.: casa (cá-sa); copo (co-po), chapéo - (cha-péo); boneca (bo-né-ca). (SANTA CATARINA, 1926, p. 8).

Em 1938, as escolas alemãs foram proibidas por leis federais: o Decreto $n^{\circ}$ 868, de 18 de novembro de 1938, criou a Comissão Nacional de Ensino Primário com responsabilização quanto à nacionalização do ensino; o de $n^{\circ}$ 948, de 13 de dezembro do mesmo ano, estabelecia que fossem concretizadas, por meio do Conselho de Imigração e Colonização, as necessárias medidas para assimilação dos colonos e a pretensa nacionalização dos filhos de estrangeiros (BOMENY, 1999, p. 158).

Para os docentes que não foram afastados durante a perseguição governista e que restaram atuantes nas escolas primárias, demandouse que fizessem as "Relações dos alunos que não falam o vernáculo". Tais listagens deviam informar os inspetores e subsidiar as ações de controle quanto ao efetivo alcance da 
nacionalização. 0 cenário confundia aqueles que ainda se dedicavam ao magistério nas regiões em que a influência cultural germânica agonizava. Veja-se o excerto de um Relatório, datado de 1944, da professora Irene Ayroso, que atuava na Escola Municipal Mista Machado de Assis, em Jaraguá do Sul:

Assumi esta escola em 1 de junho do corrente ano. Estou satisfeita com o magisterio. A Prefeitura fez alguns melhoramentos no predio escolar, dotou a escola com carteiras novas e confortáveis para os alunos, um filtro novo, uma linda Bandeira Brasileira e é solicita em atender qualquer pedido a bem desta escola.

Os livros de leitura acho que deviam ser de acordo com o grau de adiantamento da população escolar desta zona devido ao ambiente em que convivem.

As crianças fora da escola só ouvem e falam o alemão. Por isso também a eles seria mais agradável si professora fosse de origem estrangeira.

Nada mais direi a respeito visto que sou nova no magisterio e estar pouco tempo aqui nesta localidade.

Si continuar aqui mais tarde poderei dizer muito sobre o que interessa a bem da nossa querida Patria si Deus quiser. (ESCOLA MUNICIPAL MISTA MACHADO DE ASSIS, 1944).

De acordo com Seyferth (1990, p. 53), em 1930, havia mais de 1200 escolas alemãs, incluindo uma maioria de escolas primárias, mas também algumas de nível secundário, de aperfeiçoamento ou profissionalizantes. Segundo Kreutz (1994, p. 61), o temporal causado pelas campanhas de nacionalização, "desarticulou a estrutura escolar existente entre imigrantes, desmoralizando 1041 escolas comunitárias teuto-brasileiras".

Sob o violento comando de Getúlio Vargas e sua comparsaria xenófoba, as escolas alemãs ou teuto-brasileiras foram desestruturadas na sua organização etno-histórica. Foi desprezada uma contribuição para a erradicação do analfabetismo e para a boa formação da infância e juventude que vinha sendo feita há quase um século, em substituição à ausência do Estado. Resultou a extinção de várias unidades ou sua incorporação aos sistemas municipais ou estaduais. E, sofrendo enérgicas lufadas, a cultura germânica bruxuleou como velas ao vento debaixo de uma tempestade tropical.

\section{Concluindo: qual devir? O sopro do Zeitgeist}

0 teor dos escritos, quer sejam relatos de viajantes, jornais, relatórios, legislação, livros didáticos ou caderno escolar, confirma a composição analítico-interpretativa segundo a qual os contextos da imigração alemã para Santa Catarina e o inerente processo histórico de criação e transformação das instituições escolares possibilitam compreender a construção da germanidade. Sob a ótica etno-histórica, os discursos evocados corroboram perspectivas teórico-metodológicas de que agentes políticos, econômicos, sociais e culturais relacionados às atividades das instituições escolares proporcionaram a inoculação e o cultivo do Zeitgeist. Concordamos com Kreutz (1999, p. 80): o étnico é elemento central da dinâmica histórica, sendo a identidade étnico-cultural "fonte de sentido e de construção do real, mesmo se marginalizada".

Os resultados e nossas conclusões convergem com as posições de Seyferth (1990), segundo as quais as relações entre "alemães" e "brasileiros" resultaram na germanidade Deutschtum - e no germanismo teuto-brasileiro - Deutschbrasilianertum. Ou seja, a história foi instituindo o "germanizável”! Nossas análises evidenciam que tanto processos harmoniosos como embates constituíram a germanidade. A introdução, manutenção e difusão de elementos identitários por meio de práticas curriculares educativas e formativas, tanto naquelas escolas alemãs primordiais como 
naquelas teuto-brasileiras, foi sendo perpetuada de modo ciclotímico.

0 exame do fator linguístico fornece suporte para a compreensão de processos que, suportando oscilações na vitalidade do projeto educativo-formador primordial, levaram adiante a germanidade construída pelos caminhos históricos de instituição da escola em Santa Catarina. Por isso, concordamos com Appel e Muysken (1996, p. 26), que chamam atenção para o fato de que a língua suporta outras experiências étnicas e é associada à identidade cultural, ou seja, “... la lengua es el símbolo par excellence de la etnicidad".

Sobreviveu e voltou a brotar a germanidade. Em meio a adversidades históricas, foi criando profundas raízes no sul do Brasil, seja pelas influências culturais trazidas nos primeiros tempos de imigração alemã do século XIX, seja pelas resistências ao nacionalismo imposto pelo governo brasileiro em campanhas xenofóbicas. Com o passar do tempo, foram forjados níveis de integração e harmonia entre as populações em contato, criando-se diversidade étnica, aninhando-se, eliminando-se ou metamorfoseando-se tradições, hábitos e costumes culturais contrastantes.

Os processos de constituição cultural de porções meridionais do Brasil revelam a mistura de momentos de satisfação de sonhos e conquistas àqueles de dificuldades, conflitos e ambiguidades. Quanto à história das instituições escolares e seu papel, de modo geral, pode-se indicar que se perpetuaram tanto elementos positivos como traumáticos quanto ao percurso da produção cultural da germanidade, tanto pelos imigrantes alemães e sua descendência como por meio das relações com o ambiente brasileiro.

A memória da escolarização pode ser usada para reforçar e reafırmar afeição, consanguinidade e pertencimento a uma herança cultural comum, fazendo com que ainda pairem nos ares representações que perpetuam a ideia de que Santa Catarina constitui uma espécie de Europa brasileira. Há indicadores contemporâneos que mostram a preservação social da germanidade. No sistema escolar atual, boa parte das escolas oferece a língua alemã em seus currículos. Cidades catarinenses como Blumenau, Pomerode, Joinville, Brusque e Jaraguá do Sul investem na imagem de que são semelhantes a regiões europeias de onde partiram os pioneiros: realizam festas típicas, incentivam a arquitetura que reproduz edificações europeias, associando aos elementos primordiais outros que podem ser vistos como folclorização, pois, nessa composição de uma herança histórica, a divulgação turística apresenta diversas localidades como um "Vale Europeu".

A ação das escolas de imigrantes significou uma das vias de profunda penetração e manteve aceso o Zeitgeist. Torna-se possível, portanto, perguntar, como fez Santos (2012b), se há uma Alemanha perdida em Santa Catarina. Concluímos e respondemos, ratificando a instituição histórica e a permanência desse espírito alemão. Eis o elo perdido.

\section{Referências}

APPEL, René; MUYSKEN, Pieter. Bilinguismo y contacto de lenguas. Barcelona: Ariel, 1996.

AVÉ-LALLEMANT, Robert. Viagem pelo sul do Brasil no ano de 1858. Segunda parte. Rio de Janeiro: Instituto Nacional do Livro, 1953.

BECK, Nestor. L. J. Educação. In: LUTERO, Martinho. Obras selecionadas. v. 5. São Leopoldo: Sinodal; Porto Alegre: Concórdia. 1995, p. 299-301.

BINZER, Ina von. Os meus romanos: alegrias e tristezas de uma educadora alemã no Brasil. 3. ed. Rio de Janeiro: Paz e Terra, 1982.

BOMENY, Helena M. B. Três decretos e um ministério: a propósito da educação no Estado Novo. In: PANDOLFI, Dulce (Org.). Repensando o Estado Novo. Rio de Janeiro: Fundação Getúlio Vargas, 1999. p. 137-166. 
FIORI, Neide A. (Org.). Etnia e educação: a escola "alemã" do Brasil e estudos congêneres. Florianópolis: UFSC; Tubarão: Unisul, 2003. FISCHER, Joaquim. Quem é Lutero no Brasil? In: DREHER, Martin N. (Org.). Reflexões em torno de Lutero. v. 2. São Leopoldo: Sinodal, 1984. p. 53-77.

FRANCA, Leonel. 0 método pedagógico dos jesuítas (Ratio Studiorum). Rio de Janeiro: Agir, 1952.

KREUTZ, Lúcio. A escola teuto-brasileira católica e a nacionalização do ensino. In: MÜLLER, Telmo L. (Org.). Nacionalização e imigração alemã. São Leopoldo: Unisinos, 1994. p. 27-64.

KREUTZ, Lúcio. Identidade étnica e processo escolar. Cadernos de Pesquisa, São Paulo, n. 107, p. 79-96, jul. 1999.

LUTERO, Martinho. Uma prédica para que se mandem os filhos à escola. In: Obras selecionadas. v. 5. São Leopoldo: Sinodal; Porto Alegre: Concórdia, 1995. p.326-363.

MÜLLER, Telmo L. (Org.). Nacionalização e imigração alemã. São Leopoldo: Unisinos, 1994.

PANDOLFI, Dulce (Org.). Repensando o Estado Novo. Rio de Janeiro: Fundação Getúlio Vargas, 1999.

RICHTER, Klaus. A sociedade colonizadora hanseática de 1897 e a colonização do interior de Joinville e Blumenau. 2. ed. Florianópolis: UFSC; Blumenau: FURB, 1992.

SANTOS, Ademir Valdir dos. A política educacional nacionalista e 0 aspecto linguístico: vestígios na escola primária. Revista Brasileira de Estudos Pedagógicos, Brasília, v. 90, n. 225, p. 511-527, maio/ago. 2009.

SANTOS, Ademir Valdir dos. As escolas alemãs em Santa Catarina e sua transformação para teuto-brasileiras: uma análise histórica. Acta Scientiarum. Education, Maringá, v. 36, n. 2, p. 233-242, jul./dec. 2014.

SANTOS, Ademir Valdir dos. Educação e colonização no Brasil: as escolas étnicas alemãs. Cadernos de Pesquisa, São Paulo, v. 42, n. 146, p. 538-561, maio/ago. 2012a.

SANTOS, Ademir Valdir dos. Quando eu era criança... memórias da infância e da escola no cenário da imigração alemã. In: FARIA FILHO, Luciano Mendes de; ARAÚJO, Vania Carvalho de (Orgs.). História da educação e da assistência à infância no Brasil. v. 8. Vitória: Edufes, 2011. p. 97-124.

SANTOS, Ademir Valdir dos. The lost Germany: children's schooling in colonies of German immigrants in the south of Brazil. In: INTER-CONGRESS OF INTERNATIONAL UNION OF ANTHROPOLOGICAL AND ETHNOLOGICAL SCIENCES (IUAES), 2012. Bhubaneswar, 2012. Abstracts, children and youth in a changing world. Panel 9(A). Bhubaneswar: IUAES; KISS; KIIT, 2012b.

SANTOS, Ademir Valdir; VECHIA, Ariclê. Escola, imigração alemã e identidade étnica no Paraná e em Santa Catarina. Cadernos de História da Educação, Uberlândia, v. 12, n. 2, p. 395-409, jul./dez. 2013.

SAVIANI, Dermeval. História das ideias pedagógicas no Brasil. Campinas: Autores Associados, 2007.

SAVIANI, Dermeval. Tendências e correntes da educação Brasileira. In: MENDES, Durmeval Trigueiro (Coord.). Filosofia da educação brasileira. Rio de Janeiro: Civilização Brasileira, 1983. p. 19-47.

SCHADEN, Egon. Aspectos históricos e sociológicos da escola rural teuto-brasileira. In: COLÓQUIO DE ESTUDOS TEUTO-BRASILEIROS, I., 1963, Porto Alegre. Anais do primeiro colóquio de estudos teuto-brasileiros. Porto Alegre: UFRGS, 1966. p. 65-77.

SEIDLER, Carl. Dez anos no Brasil. São Paulo: Livraria Martins, 1941.

SEYFERTH, Giralda. A colonização alemã no vale do Itajaí-Mirim: um estudo de desenvolvimento econômico. 2. ed. Porto Alegre: Movimento, 1999.

SEYFERTH, Giralda. Imigração e cultura no Brasil. Brasília: UnB, 1990.

VIÑAO, Antonio. Os cadernos escolares como fonte histórica: aspectos metodológicos e historiográficos. In: MIGNOT, Ana Chrystina Venancio (Org.). Cadernos à vista: escola, memória e cultura escrita. Rio de Janeiro: Eduerj, 2008, p. 15-33. 
WEREBE, Maria José G. A educação. In: FAUTO, Boris; HOLANDA, Sérgo Buarque de. História geral da civilização brasileira: 0 Brasil monárquico - dispersão e unidade. 5. ed. t. 2. v. 4. Rio de Janeiro: Bertrand Brasil, 1995. p. 366-383.

WILLEMS, Emílio. A aculturação dos alemães no Brasil. 2. ed. São Paulo: Nacional, 1980.

\section{Fontes documentais}

ANDREE'S, Richard. Allgemeiner handatlas in sechsundachtzig karten mit erläuterndem text. Bielefeld und Leipzig: Verlag von Velhagen \& Klasing, 1881.

A ORTHOEPIA da lingua portugueza em exercicios para as escolas allemãs no Brasil. 22. ed. São Leopoldo: Porto Alegre: Cruz Alta: ljuí: Rotermund, 1920.

AUSZUG aus den Schulberichten im Bezirt Itapocú pro 1904. Hammonia, 1905.

BÜCHLER, Georg August; Zimmermann, Erich. Portugiesisches Sprachbuch für Kolonieschulen. Blumenau: G. Arthur Koehler, 1914.

BÜCHLER, Otto. Arithmetica pratica em quatro partes. 5. ed. São Leopoldo: Porto Alegre: Cruz Alta: ljuí: Rotermund, 1915. Tradução Homero Dias Cardozo.

BÜCHLER, Otto. Praktische Rechenschulle in der heften für Deutsche Schulen in Brasilien. 4. heft. São Leopoldo: Verlag Rotermund, [19_.].

CADERNO, Kilian Tank. Lingua portugueza: tradução. Guaramirim: [s. n.], 1946.

EBLING-ROTERMUND. Minha língua: grammatica portuguesa para uso nas escolas allemãs no Brasil = Portugiesisches sprachbuch für die deutschen schulen in Brasilien. São Leopoldo: Verlag Rotermund, [19_..].

ESCOLA MUNICIPAL MISTA MACHADO DE ASSIS. Relatório referente à fórmula n. 2. 1944.

EY, Luise. Kleine portugiesische sprachlehre. Heidelberg: Julius Groos; Verlag, 1936.

GRIMM, M.; BÜRGER, P. Deutsches lesebuch für brasilien für das erste und zweite schuljahr nebst anhang für den deutschportugiesischen unterricht. Porto Alegre: Typographia Mercantil, 1928.

JAHRESBERICHT 1904 uber die 5 Hansaschulen des Bezirks Hercilio, erstattet von Schulinspektor Dr. Aldinger. Hammonia, 1905.

JORNAL DE JOINVILLE. Joinville. 1926.

KOLLATZ, T. Mein kleines lesebuch für das 2. schuljahr mit scherenschnitten: herausgegeben von deustchen evangelischen lehrerverein von Rio Grande do Sul. São Leopoldo: Verlag Rotermund, 1934.

SANTA CATARINA. Programma de ensino das escolas isoladas das zonas coloniaes approvado pelo Decreto no. 1944, de 27 de fevereiro de 1926. Florianópolis: Imprensa Oficial, 1926.

SELLIN, H. W. Landeskunde der vereinigten staaten von brasilien: für deutsche schulen in brasilien. Ortsgruppe Hamburg,1909. STYSINSKI, B. Grundriss der geschichte brasiliens. São Leopoldo; Cruz Alta: W. Rotermund, [19_..].

Recebido em: 15.07.2014

Aprovado em: 07.10.2014

Ademir Valdir dos Santos é pedagogo, mestre e doutor em educação pela Universidade Federal de São Carlos (UFSCar), docente e pesquisador do Departamento de Estudos Especializados em Educação, do Centro de Ciências da Educação da Universidade Federal de Santa Catarina, dedicado à etno-história. Líder do Grupo de Estudos e Pesquisas em História da Educação e Instituições Escolares de Santa Catarina (GEPHIESC). 